\title{
FLUX AND PERFORMANCE IMPROVEMENT IN A SUBMERGED ANAEROBIC MEMBRANE BIOREACTOR (SAMBR) USING POWDERED ACTIVATED CARBON (PAC)
}

\author{
Aurangzeb Akram and David C. Stuckey ${ }^{*}$ \\ Department of Chemical Engineering and Chemical Technology Imperial College \\ London, Prince Consort Rd., London SW7 2AZ, U.K. (Corresponding author). E- \\ mail: d.stuckey@imperial.ac.uk. Tel.: +44 (02075) 945591
}

\section{ABSTRACT}

Three 3 litre submerged anaerobic membrane bioreactors (SAMBRs) were used to examine the effect of powdered activated carbon (PAC) on COD removal and flux. 98 $\%$ COD removal efficiency was achieved at a high loading rate $\left(16 \mathrm{gCOD} \mathrm{l^{-1 }} \mathrm{d}^{-1}\right)$ at a low HRT of 6 hours in the presence of $3.4 \mathrm{~g} \mathrm{l}^{-1}$ of PAC. PAC addition improved startup and performance during a hydraulic shock by buffering the VFAs, however, a large amount of biomass was important in accommodating the higher loading rate in the SAMBR. Batch assays showed that PAC addition improved methane potential both in terms of amount and inoculation time. COD retention inside the SAMBRs was proportional to the soluble microbial products (SMPs) contribution to COD, as volatile fatty acids (VFAs) passed through the membrane at high sparging rates (5 litres per minute-LPM). Size exclusion chromatography showed that the membrane acted as an ultra-filter $(<30 \mathrm{kDa}$ as the cake or gel layer significantly reduced the amount of organics passing through the membrane. PAC adsorbed slowly biodegradable low and high MW residual COD from the bulk liquid, and hence improved COD removal and flux. Particle size distributions demonstrated that PAC also adsorbs fine colloids, and flux data showed that only a thin biofilm was formed due to the high backtransport velocity of PAC. The combined effects of adsorption of fine colloids and dissolved organics, and the formation of a thin cake layer resulted in significant flux improvement from 2 to 9 litres per square metre per hour (LMH) in the presence of $1.67 \mathrm{~g} \mathrm{l}^{-1}$ PAC. However, addition of $3.4 \mathrm{~g} \mathrm{l}^{-1}$ PAC reduced the flux to $5 \mathrm{LMH}$ by the combined effect of viscosity and its inability to completely adsorb the dissolved organics and fine colloids that resulted in high internal fouling. Under the given operating conditions, addition of $1.67 \mathrm{~g} \mathrm{l}^{-1}$ PAC appears to be the optimum quantity in terms of cost, flux and soluble COD removal. 
Key Words- Soluble microbial products (SMP), Colloids, Extracellular polymers (ECPs), Critical Flux, Effluent, Anaerobic digestion, Membrane bioreactor , Powdered activated carbon (PAC).

\section{INTRODUCTION}

The stability and performance of biological treatment processes is intimately related to biomass retention, and membrane bioreactors (MBRs) have been used for this purpose to physically retain microorganisms inside the reactor to produce solids free and better quality effluents $[1,2]$. Despite good COD removals and high loading rates, MBR systems often suffer from flux decline due to membrane fouling. Membrane fouling may be attributed to external fouling due to cake formation as a result of the adsorption of soluble organics and biopolymers, the attachment of microbial cells and fine colloids, and the deposition of inorganic precipitates on the membrane surface [3]. In addition, it can also be due to internal fouling as a result of membrane pore clogging by fine colloids [4], and the adsorption of dissolved organics (mainly SMP) inside the pores [5]. Various approaches have been adopted to prevent fouling such as increasing fluid velocity [6], increasing fluid pumping or gas sparging rate, relaxation, backwashing [7], modifying the membrane surface [8], sub critical flux operation [9], and the addition of powdered or granular activated carbon $[3,5]$.

Most of the above methods involve high capital, operational and replacement costs, however, addition of powdered activated carbon (PAC) has proved to be a robust and cost effective approach, not only for flux enhancement, but also for improved COD removal during shock loading [3]. However, the relative importance of PAC in flux enhancement due to the effect of physical scouring of the membrane surface, lowering of specific cake resistance, or adsorption of fine colloids and dissolved organics is not clear. The objectives of this study were to understand in more depth the exact role of 
PAC in flux improvement, and to optimise its concentration in order to generate the maximum possible flux in a SAMBR. If flux is improved by PAC addition, it would also be interesting to observe the maximum organic loading rate capacity of the SAMBR in terms of lowest possible HRT, and system behaviour under high sludge and organic loading rate. Finally, since it is crucial to achieve a high and stable removal efficiency in the shortest possible time during start-up, it is also important to understand the ability of PAC to adsorb VFAs.

\section{MATERIALS AND METHODS}

\section{Experimental Setup}

The experimental set up used for this study is shown in Figure 1. Each SAMBR had a working volume of 3 litres, and was made of acrylic panels. Each reactor contained a micro-filtration membrane module $\left(0.1 \mathrm{~m}^{2}, 0.4 \mu \mathrm{m}\right.$ pore size, polypropylene $)$ and an internal vertical hanging and standing baffle designed to direct the fluid to the upcomer and downcomer regimes. The biomass was continuously mixed using headspace biogas that was pumped (B100 SEC, Charles Austin) through a stainless steel tube diffuser to generate coarse bubbles. The bubbles pushed the liquid upward across the membrane module and provided necessary cross-flow velocity. To avoid excessive fouling, a constant sparging rate of 5 LPM was maintained during all experiments using a gas flowmeter (ColeParmer, USA). The feed and effluent streams were controlled by Watson-Marlow variable speed peristaltic pumps (Model 101U) and maintained at the same flow rate based on an operational HRT. Total permeate flux was adjusted by peristaltic pump to $10 \mathrm{LMH}$ as it was expected that maximum flux in the presence of PAC would be higher than this; permeate in excess of the 
effluent stream was recycled back to the reactor. Although a mass flow meter (Model 101-3) monitored the total flux, in most cases it was lower than the range of the flow meter because of excessive fouling. Therefore, the flux was measured manually using a calibrated cylinder and a stop watch. A TMP transducer (PMP 1400, RS components) measured pressure difference across the membrane module, and data was recorded with HP VEE software using a data logging system. The reactor was operated at $35 \pm 1^{\circ} \mathrm{C}$ in a water bath, and sodium bicarbonate was added to the feed to maintain a neutral $\mathrm{pH}$.

Screened sludge acclimatised in a SAMBR in previous work [10] was used to ensure that the first experiment achieved steady state quickly. The same sludge was used to carry out the experiments with PAC by adding appropriate quantities to the biomass, however, a dormant period (no feeding at room temperature) of two months was provided between the start-up of each experiment. PAC (Norit, UK) was screened through a $100-\mu \mathrm{m}$ sieve and dried in an oven at $105^{\circ} \mathrm{C}$ overnight. The detailed characteristics of the PAC are listed elsewhere [10]. Concentrations of $1.67 \mathrm{~g} \mathrm{l}^{-1}$ and $3.4 \mathrm{~g} \mathrm{l}^{-1}$ of PAC were added for the second and third experiments.

\section{Chemical Analysis}

Effluent samples were centrifuged at 13,000 rpm (Biofuge Stratos, Heraeus Instruments) for $20 \mathrm{~min}$ and filtered through $0.45 \mu \mathrm{m}$ Sartorius filters; hence "soluble" for this study was any material passing through $0.45 \mu \mathrm{m}$ filters. Samples were analysed in duplicate for COD, glucose, VFAs and SMP. SMP concentration was determined by difference [11]. 
$\mathrm{COD}$ coefficient of variance $(\mathrm{CV}== \pm 5 \%)$ measurement was based on the "closed reflux, colorimetric method" described in Section 5220-D of Standard Methods [12]. Total suspended solids (TSS) $(\mathrm{CV}== \pm 5 \%)$ and volatile suspended solids (VSS) $(\mathrm{CV}== \pm 5 \%)$ were measured according to the modified procedure described in section 2540-B and 2540-E of Standard Methods [12], where centrifugation instead of filtration was used. $\mathrm{pH}$ was measured using a $\mathrm{pH}$ meter (Jenway, Model 3020) calibrated with buffer solutions of $\mathrm{pH} 4$ and 7.

\section{Liquid Chromatography}

For size exclusion chromatography (SEC) an Aquagel OH-30 column (Polymer Labs) was used with deionised water as an eluent at a flow rate of $1 \mathrm{ml} \mathrm{min}{ }^{-1}$ in a Shimadzu (Model 10A) HPLC. The sample volume was $50 \mu \mathrm{l}$, and the column was maintained at ambient temperature; the UV detector was set at $210 \mathrm{~nm}$ for detection of the separated compounds. Unbranched standards of polyethylene oxide (PEO) and polyethylene glycol (PEG) were used to calibrate the system and detected by Refractive Index (RI) detector. The results obtained are quoted relative to these linear standards.

VFAs and glucose were separated by an Aminex HPX-87H ion exclusion column (300 $\mathrm{mm} \times 7.8 \mathrm{~mm}$ ) using $0.01 \mathrm{M} \mathrm{H}_{2} \mathrm{SO}_{4}\left(0.7 \mathrm{ml} \mathrm{min}^{-1}\right.$ ) as the mobile phase. The injection volume was $50 \mu \mathrm{l}$, the column temperature was $55^{\circ} \mathrm{C}$, and the UV detector was set at a wavelength of $210 \mathrm{~nm}$. For glucose the detection was made using a Shimadzu (Model 10A) refractive index (RI) detector. The peak area was calculated and printed out by Class-VP (version 5.07) software. 
Reports in the literature [13] suggested that GAC did not adsorb VFAs, but since our data implied that PAC do, a batch assay was carried out. The buffer ability of PAC to adsorb VFAs was determined in sealed serum bottles at $35^{\circ} \mathrm{C}$ where PAC was added to mixtures (50:50) of acetate and propionate with a maximum COD of $2 \mathrm{~g} \mathrm{COD} \mathrm{1}^{-}$ ${ }^{1}$ while the serum bottles were shaken at $200 \mathrm{rpm}$ inside the incubator. It was found that VFAs were completely adsorbed by PAC within 24 hours of addition.

\section{Biochemical Methane Potential (BMP) Assays}

The assay was conducted using the media and modified serum bottle technique reported by Owen et al. [14]. The details about preparation of serum bottles is described elsewhere [10] where initial glucose concentration was maintained at $2 \mathrm{~g}$ COD $1^{-1}$. All serum bottles were equilibrated at $35^{\circ} \mathrm{C}$, and zeroed $10 \mathrm{~min}$ after substrate addition. Methanogenic activity was monitored by measuring the composition and volume of gas produced over time. Biogas composition was monitored using a Shimadzu GC-TCD (Model 14A) fitted with a Porapak N column $(1500 \times 6.35 \mathrm{~mm})(\mathrm{CV}= \pm 2 \%)$. Biogas produced was measured using a glass syringe and wasted after each measurement. Triplicate samples were carried out for each sample $(\mathrm{CV}= \pm 3 \%)$

\section{Particle Size Measurement}

Particle size measurements were made using a Malvern Instruments Particle Size Analyser (Model 2600C) with a helium neon laser, and operated with Mastersizer 2000 software. Samples were carefully collected from the centre of the reactor bed using a syringe. The standard deviation for average particle size was within $\pm 5 \%$. 


\section{Flux Experiments}

The relative contribution of each component of fouling (external fouling due to cake formation, internal fouling due to clogging of fine colloids, and dissolved organics inside the membrane pores) was measured during all three experiments. The experiments measured the flux manually by collecting permeate for a given time through the membrane driven by a hydrostatic head that corresponded to 0.2 bars TMP. The maximum permissible flux for a clean membrane (F4) was $200 \mathrm{LMH}$ at this TMP. The flux in the presence of internal and external fouling was measured manually with a biofilm containing fouled membrane and subtracted from F4 to obtain the flux drop due to the combined effect of internal and external fouling (F1). The biofilm was scrapped from the membrane surface and the flux in the presence of internal fouling alone was measured and subtracted from F4 to get the flux drop due to internal fouling alone (F3). Flux drop due to biofilm alone (F2) was obtained by subtracting F1 and F3.

\section{RESULTS AND DISCUSSION}

\section{Overall Performance of SAMBRs during Start-up}

Table 1 shows the performance of the SAMBRs at different HRTs, and in the presence of different amounts of PAC. Since screened sludge which had been acclimatised and adapted in a SAMBR was used, the initial start-up was set at a HRT of 40 hours for the reactor without PAC, and 30 hours with PAC. In an experiment without PAC the system achieved steady state COD removal of $96 \%$ at 20 hours HRT in 33 days for 4 gCOD $1^{-1}$, while it took 52 days to bring the HRT down to 15 
hours in steps to achieve a COD removal of $96 \% .1 .67 \mathrm{~g} \mathrm{l}^{-1}$ PAC was added to the biomass and the experiment was restarted with a clean membrane at 30 hours HRT after giving the biomass a dormant period of two months (i.e. not feeding). The SAMBR with $1.67 \mathrm{~g} \mathrm{l}^{-1}$ PAC achieved steady-state removal of $99 \%$ in 18 days, after which loading rates (both sludge and organic) were increased in one large step by reducing the HRT from 20 down to 6 hours (low HRT was possible due to flux improvement by PAC addition). The performance of the system dropped to $88 \%$, mainly due to VFA accumulation (Figure 2) and their leakage into the effluent (Table 2). COD removal stayed at this value even after 10 days of change, which shows a slight overloading of the microorganisms involved in the degradation of VFAs. The performance drop was not significant due to the buffering capacity of PAC. SAMBR 1 (2) containing $1.67 \mathrm{~g} \mathrm{l}^{-1}$ PAC recovered to $99 \%$ COD removal at 15 hours HRT immediately (within 12 hours) after cessation of the load.

In the third experiment, a further $1.67 \mathrm{~g} \mathrm{l}^{-1} \mathrm{PAC}$ (giving in total $3.4 \mathrm{~g} \mathrm{l}^{-1}$ ) was added to the diluted biomass from the previous experiment, and the reactor was started with a clean membrane. This was to study the role of PAC in cake formation and hence fouling of the membrane during start-up. SAMBR 1 (3) containing $3.4 \mathrm{~g} \mathrm{l}^{-1}$ PAC reached $98 \%$ COD removal in 17 days at 20 hours HRT, after which the retention time was decreased in steps to 12 hours and then to 6 hours HRT which resulted in a gradual increase in loading rate. The SAMBR achieved steady state performance of $98 \%$ removal in 30 days at 6 hours HRT.

Table 3 shows the performance of the SAMBRs at their lowest possible HRTs and maximum possible loading rates. In the absence of PAC, the highest performance (97 
$\%$ removal) at an organic loading rate (OLR) of $6.4 \mathrm{~g} \mathrm{COD}^{-1} \mathrm{~d}^{-1}$ was achieved in 52 days, while the sludge loading rate (SLR) was maintained at $0.52 \mathrm{~g} \mathrm{COD} \mathrm{g}^{-1} \mathrm{VSS} \mathrm{d}^{-1}$. A biomass level of $12 \mathrm{~g} \mathrm{l}^{-1}$ was maintained at the end of the experiment which kept

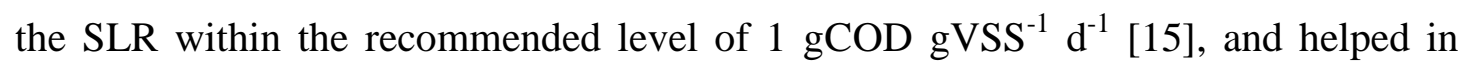
starting the system at high OLRs without any VFA accumulation. The total SMP production and normalised SMP was higher, and the value of the later was in the range of 0.45 , and agreed with the trend observed by Aquino et al. [5] who showed that the normalised SMP was higher in systems with higher biomass retention. With

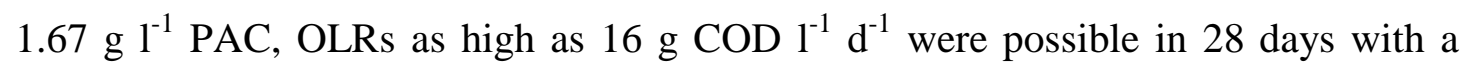
COD removal of $88 \%$. This slightly lower efficiency was due to the presence of VFAs in the effluent (as described before), and was attributed to the low biomass concentration leading to a much high value of SLR (1.4 $\left.\mathrm{g} \mathrm{COD} \mathrm{g}^{-1} \mathrm{VSS} \mathrm{d}^{-1}\right)$. However, SMPs inside the reactor reduced significantly presumably due to the adsorption of organics by PAC that were difficult to biodegrade, and were contributing to residual COD inside the reactor. From Table 3 it is clear that around $1269 \mathrm{mgCOD}^{-1}$ (equal to $70 \%$ of total COD) inside the reactor was adsorbed by the addition of $1.67 \mathrm{~g} \mathrm{l}^{-1}$ of PAC. The MW distribution of the bulk liquid determined by ultrafiltration [5] showed that around $30 \%$ of the total COD in the reactor without PAC was due to high MW organics (data not shown). Hence $1.67 \mathrm{~g} \mathrm{l}^{-1}$ of PAC adsorbed at least $40 \%$ of dissolved organics $\left(715 \mathrm{mg} \mathrm{COD}^{-1}\right.$ ) belonging to the low MW fraction, implying that PAC can adsorb both high and low MW dissolved organics.

In the presence of $3.4 \mathrm{~g} \mathrm{l}^{-1}$ PAC, $98 \%$ COD removal was achieved in 30 days at 6 hours HRT, corresponding to an OLR of $16 \mathrm{gCOD}^{-1} \mathrm{~d}^{-1}$. The reason for this higher 
removal seems to be related to the gradual increase in the loading rate, and higher biomass level of $16 \mathrm{~g}^{-1}$ resulting in an improved SLR of $1.0 \mathrm{gCOD} \mathrm{gVSS}^{-1} \mathrm{~d}^{-1}$. Apart from a high biomass concentration, a possible change in biomass composition over time with an enrichment of slow growing microorganisms seems to be responsible for the stable and better performance of SAMBR 1 (3). Compared to its initial value, the reactor SMPs were slightly higher at the end of experiment; possibly there is some high MW residual COD which is non-absorbable on PAC. It is unlikely that a constant SMP inside the SAMBR is a result of the exhaustion of PAC capacity due to modification of its surface. Previous results revealed that PAC maintained its characteristic properties even after three months of use in a SAMBR [16]. From the results of the above three experiments, it is clear that the addition of PAC improved performance during start-up, and a higher concentration and enrichment of biomass allowed the system to handle higher organic and sludge loading rates with high COD removal efficiencies.

\section{Solids concentration}

Figure 3 demonstrates the variation in biomass concentrations with time for the three experiments. From SAMBR1 (1), it is clear that although a higher initial VSS level was used, the increase in VSS was not so high because the increase in loading rate was gradual, and stabilised at a lower value of $6.4 \mathrm{gCOD}^{-1} \mathrm{~d}^{-1}$, resulting in a biomass concentration of $12 \mathrm{~g} \mathrm{l}^{-1}$. In the second case, biomass increased gradually from $6 \mathrm{~g}^{-1}$ to $12 \mathrm{~g} \mathrm{l}^{-1}$ with an increase in OLR to $16 \mathrm{gCOD}^{-1} \mathrm{~d}^{-1}$, however, if a slightly longer time had been provided for the development of VSS at this loading rate the performance of the reactor might have improved from $88 \%$ COD removal due to the 
build up of biomass. For the third experiment with the stepwise increase in loading rate from 3.2 to $16 \mathrm{~g} \mathrm{COD}^{-1} \mathrm{~d}^{-1}$, the biomass concentration increased to $16 \mathrm{~g} \mathrm{l}^{-1}$ which provided a sufficiently low SLR for high COD removal. The difference between TSS and VSS values increased for the third experiment which showed that more of the solids other than biomass were produced over time and accumulated in the reactor. These solid materials consisted of fine colloids and other compounds that might have been produced due to cell lysis or PAC attrition. At the end of the experiment, the value of total suspended solids including $3.4 \mathrm{~g} \mathrm{l}^{-1} \mathrm{PAC}$ was around 23 $\mathrm{g}^{-1}$, which in the presence of higher values of ECP contributed to a higher viscosity (7 centipoises) of the bulk liquid.

\section{SMP production during start-up}

Figure 2 shows the VFA and SMP profile inside the reactors over time. SMP production and accumulation was higher without PAC addition (SAMBR1 (1)), and the residual COD increased from $1500 \mathrm{mg} \mathrm{l}^{-1}$ at the start to higher values with each decrease in HRT. This increased production of SMPs due to catabolism and cell lysis is associated with stresses at low HRT and high loading rates [10], and their accumulation demonstrates their slower biodegradability. Schiener et al. [18] also reported that all MW fractions of the SMPs produced in anaerobic digestion were less degradable anaerobically, and found that the high MW fraction consisted of organics that were cell wall constituents. Therefore, it is possible that enhanced cell lysis due to high cell ages of the biomass in SAMBR 1 (1) contributed to the enhanced accumulation of SMP. 
As it was difficult to degrade residual COD, these organics were adsorbed by the addition of $1.67 \mathrm{~g} \mathrm{l}^{-1}$ PAC to the SAMBR, which resulted in improved flux and better COD removal. The results also show very low accumulation of VFAs with PAC addition, indicating that the HRT can be decreased further if the flux is sufficiently high. This flux improvement is also possible if the membrane surface area is doubled by the addition of another Kubota module below the existing one [10]. In the second and third experiment VFAs increased initially due to initial higher loading rate and low HRT (30 hrs), but the values dropped after 10 days. With the decrease in HRT, VFAs remain low except during the high loading rate at 6 hours HRT when increased level of VFAs (mainly acetate and propionate) in the reactor and effluent reduced COD removal efficiency. It is interesting to note that the residual COD values during the experiment remained lower, possibly due to the PAC adsorption of excessive SMP produced. Also the constant SMP level up to day 28 shows an equilibrium had occurred between -production, adsorption and degradation of organics on the PAC surface. The reduction in SMP thereafter -demonstrated enhanced biodegradation of sorbed organics and regeneration of PAC to further remove residual COD. The same trend of a decrease in bulk residual COD was observed with $3.4 \mathrm{~g}^{-1}$ PAC from day 12 that reinforces the hypothesis of biodegradation of organic compounds sorbed on PAC, and that higher amounts of PAC proportionally enhanced biodegradation. From day 20 onwards SMPs start increasing again due to their excessive production at high biomass concentrations $\left(12 \mathrm{~g} \mathrm{l}^{-1}\right)$ where SMP values stayed constant at a slightly higher value of $350 \mathrm{mg} \mathrm{l}^{-1} \mathrm{PAC}$ [units??]. This demonstrated that PAC was unable to adsorb all of the residual COD and reached a new equilibrium condition. In this experiment, VFAs appeared at 20 hours HRT and consisted of acetate and propionate. 
VFA levels persisted (mixture of all VFAs) until the drop in HRT to 12 hours, after which no significant accumulation was observed even at 6 hours HRT.

In addition, Table 2 shows that soluble reactor COD was significantly higher than the effluent COD in all three experiments, and this difference was quite pronounced for the reactor operating without $\mathrm{PAC}$ where the reactor to effluent $\mathrm{COD}$ ratio was highest ( 12). This COD concentration difference is attributed either to rejection by the gel layer on the surface of the membrane, or degradation or retention by the biofilm on the membrane surface, or due to internal fouling, or all of these factors. Huang et al. [19] studied an aerobic MBR and found that most soluble organic compounds, which were metabolic products and SMP, were retained by membrane filtration and accumulated in the bioreactor, thereby upgrading the effluent quality. The retention was also proportional to the COD concentration and COD contribution of microbial metabolic compounds [10], as observed for the experiment without PAC, and in the case of $3.4 \mathrm{~g} \mathrm{l}^{-1}$ PAC addition where COD retention was higher as VFAs contribution to COD was negligible. In the presence of $1.67 \mathrm{~g}^{-1}$ PAC the majority of the COD (292 $\left.\mathrm{mg} \mathrm{l}^{-1}\right)$ at 6 hours HRT was comprised of VFAs that permeated the membrane (data not shown) and resulted in a low value of reactor to effluent COD (1.1). It is also expected that the thicker the membrane film the more organics will be rejected, especially those with higher MWs as is clear from Figure 5a-c, where the cake layer was much thicker in the first experiment resulting in a significant retention of organics.

\section{Molecular Weight Distribution}


Figure 6 presents the size exclusion chromatograms of the supernatant (A) and effluent (B) present in all the three experiments, and extracted ECP (C) for the second experiment before and after applying a high loading rate. In size exclusion chromatography (SEC), high MW compounds elute first from the column and hence appear at low retention times, whilst for small molecules the converse is true. Standards (polyethylene glycol and polyethylene oxide) were used to calibrate the Aquagel OH-30 column, and good separation was obtained in the range of $0.2-43 \mathrm{kDa}$ (Figure 6d).

The data presented in Figure 6a indicates that PAC was effective in adsorbing high MW SMP, and hence reduced the residual COD inside the reactor; Aquino et al. [5] have presented similar evidence. These authors used both granular activated carbon (GAC) and PAC to remove dissolved organic compounds in anaerobic reactor bulk liquid and effluent and showed that low MW compounds $(<1 \mathrm{kDa})$ were more difficult to adsorb than the high MW compounds (>1 kDa). The addition of $1.67 \mathrm{~g} \mathrm{l}^{-1}$ PAC significantly reduced the high MW organics in the reactor, however, the further addition of another $1.67 \mathrm{~g} \mathrm{l}^{-1}$ PAC did not reduce the amount of remaining high MW compounds any further. This might be because the remaining non-adsorptive substances have a low affinity for PAC, or that the carbon surface has been modified due to the adsorption of organics [20,21].

The bulk liquid and effluent chromatograms (Figure 6a, b) suggest that organics with a MW higher than $30 \mathrm{kDa}$ (approximately) were present in significant quantities inside the reactor, but were mainly retained by the membrane since their concentration in the effluent was insignificant. This may indicate a membrane cut-off of $\sim 30 \mathrm{kDa}$ 
which results from the narrowing of pores of the membrane caused by biomass colonisation on the membrane surface [22], and by adsorption of SMP and fine colloids inside the pores [5]. The same MW cut-off of the membrane has already been reported for SAMBRs for low strength wastewater treatment [5]. This means that the fouled membrane acts as an ultrafilter rather than a microfilter and hence had a significantly lower flux than a clean membrane. It is clear from Figure $6 \mathrm{~b}$ that a small amount of organics in the size range of $30-50 \mathrm{kDa}$ were also present in the effluent of the reactor containing $1.67 \mathrm{~g} \mathrm{l}^{-1}$ of PAC; probably due to the presence of a thin cake layer (Figure 5) and/or less internal fouling of the membrane (Table 4). This lower retention of high MW organics is another reason for the low ratio of reactor to effluent COD seen in Table 2. Shin and Kang [23] showed that $57 \%$ of the SMP produced in an aerobic MBR was retained by the membrane due to reduced MW cut-off, and as a result the effluent dissolved organic carbon (DOC) averaged $1.8 \%$ of the influent DOC. Figure $6 \mathrm{~b}$ also shows that none of the organics with a MW of $30 \mathrm{kDa}$ or more appeared in the effluent in the presence of $3.4 \mathrm{~g} \mathrm{l}^{-1}$ PAC. The authors believe that the presence of PAC in a thin fouling layer adsorb these organics completely during their permeation and further reduced the molecular cut-off range, thereby improving the removal efficiency of soluble organics (Table 1) fbut did you see any PAC in this layer?].

By comparing the chromatograms of extracted ECP (Figure 6c) with the bulk solution (Figure 6a) it appears that there is a match in the compounds that appear at $\sim 4-8$ min. retention time. Therefore, it is likely that some of the high MW compounds present in the bulk solution for each experiment are due to the extracellular polymers (ECPs) released from the cells in the reactor [5]. Laspidou and Rittman [24] believe that ECP 
production is a mechanism for cell protection and energy storage. As ECP production is much higher during high loads, it seemed that the biomass excreted more ECP to cope with stress and to protect cells [25].

\section{Particle Size Distribution}

An analysis of particle size distribution of PAC and sludge from the SAMBR for three experiments can be seen in Figure 7. The results show that the particle size distribution of PAC ranged from 1 to $200 \mu \mathrm{m}$, with a Sauter Mean diameter of $28 \mu \mathrm{m}$, while the sludge from the three experiments show less broad size distributions with decreasing Sauter particle sizes with the addition of PAC. This shift in particle size distribution of anaerobic sludge with PAC addition $\left(1.67 \mathrm{~g} \mathrm{l}^{-1}\right.$ and $\left.3.4 \mathrm{~g} \mathrm{l}^{-1}\right)$ to a smaller size compared with that of sludge without PAC was due to the contribution of the relatively small PAC added [26]. In general, biomass in the SAMBR consisted of weak flocs which were easily broken under a turbulent environment and PAC attrition leading to a decrease in floc size. The destruction of flocs promotes the release of ECP or SMP to the bulk solution, causing more internal fouling (Table 4) [27]. Pianta et al. [28] showed that submicron particles have an important impact on membrane permeability, and previous findings on a SAMBR treating low strength wastewater also showed that small submicron (size $<1 \mu \mathrm{m}$ ) particles led to pore clogging as their size is comparable to the pore size of the Kubota membrane [5]. When comparing the addition of 1.67 and $3.4 \mathrm{~g} \mathrm{l}^{-1} \mathrm{PAC}$, it can be seen that both adsorbed all the fine colloids of less than $0.6 \mu \mathrm{m}$ (Figure 7), which demonstrates the ability of PAC to adsorb colloids and hence improve flux. 


\section{Transmembrane Pressure (TMP) and Flux}

Figure 8 shows the change in TMP over time at a constant flux of $10 \mathrm{LMH}$ for the experiment without PAC, and with $1.67 \mathrm{~g} \mathrm{l}^{-1}$ PAC. In the absence of PAC, TMP stabilised at around 0.23 bars during the experiment. Based on a maximum flux of 2 $\mathrm{LMH}$, the critical flux for this experiment was much lower. The pragmatic critical flux experiment does not demonstrate clearly TMP changes over the long run; therefore total recycle was maintained at $10 \mathrm{LMH}$ which was the maximum permissible flux for the experiment with $1.67 \mathrm{~g}^{-1}$ PAC addition. Figure 8 also shows that the TMP rise in the presence of PAC was gradual (18 days). Li et al. [27] also showed that during long-term operation of an aerobic SAMBR at constant flux, the TMP increase with PAC could be lagged, and thus the operating interval could be extended about 1.8 times compared to the system without PAC. The TMP stabilised at 0.1 bars at $10 \mathrm{LMH}$ which indicated lower cake resistance and less membrane fouling with PAC addition, and showed that the SAMBR can be operated for some time at constant flux. Guo et al. [29] have reported increases in filtration (permeate) flux of microfiltration by the incorporation of PAC as a pre-treatment method, where PAC adsorption led to a six times higher critical flux than without. The TMP increased to 0.25 bars only when the recycle flux was increased to $15 \mathrm{LMH}$, which shows that around $10 \mathrm{LMH}$ was the critical flux in the presence of $1.67 \mathrm{~g} \mathrm{l}^{-1} \mathrm{PAC}$ under the given operating conditions, however, the TMP dropped back to a very low value when the flux was reduced to $10 \mathrm{LMH}$ showing that the membrane fouling was reversible.

Although the total suspended solids of the sludge with PAC addition were higher than without PAC, and the floc size was reduced as well, the membrane permeability of 
sludge with $1.67 \mathrm{~g} \mathrm{l}^{-1} \mathrm{PAC}$ was greatly enhanced. The increase in flux was due to the adsorption of colloids (Figure 7) and dissolved organics (Table 3). Furthermore, Park et al. [3] also observed that PAC particles contribute to an increase in biosolids backtransport, leading to a reduction in cake layer resistance and thinner cake formation thus resulting in flux improvement. From the results of $\mathrm{Hu}$ and Stuckey [16] it was concluded that the greater surface area of PAC compared to GAC helped to improve the operating flux and critical flux in a SAMBR. Park et al. [3] also reported increased flux with increasing PAC doses up to $5 \mathrm{~g}^{-1}$. Hence a further $5 \mathrm{~g}$ of PAC was added (which gave $3.4 \mathrm{~g} \mathrm{l}^{-1} \mathrm{PAC}$ ) in an attempt to improve flux. However, the maximum possible flux in this case was $5 \mathrm{LMH}$ compared to $9 \mathrm{LMH}$ for $1.67 \mathrm{~g}^{-1}$ PAC, which showed the dependence of flux on the amount of total suspended solids and bulk composition, and hence on viscosity of the bulk phase. The addition of $3.4 \mathrm{~g}$ $1^{-1}$ PAC to the SAMBR caused a flux decline probably because of a significant increase in viscosity to $7 \mathrm{cp}$. These results of lower fluxes with an increase in PAC dosage conflict with those reported in the literature [3]. However, studies have shown that the role of PAC in flux improvement depends on the amount of PAC added [30], solution chemistry [31], and type and concentration of dissolved organic compounds [32].

In the first experiment without PAC, the available flux was $2 \mathrm{LMH}$, where internal fouling contributed to a flux drop of $160 \mathrm{LMH}$, and the cake layer contributed to a flux drop of $38 \mathrm{LMH}$, out of $200 \mathrm{LMH}$ of total available flux (Table 4). These findings encouraged the use of PAC as a scouring agent and as an adsorbent media to reduce cake layer resistance and internal fouling, respectively. With the addition of $1.67 \mathrm{~g}^{-1}$ PAC the flux improved significantly to $9 \mathrm{LMH}$ at the end of the experiment, 
at a total solids level of $16 \mathrm{~g} \mathrm{l}^{-1}$ and a viscosity of $1.32 \mathrm{cp}$. In order to further improve the flux, another experiment with $3.4 \mathrm{~g} \mathrm{l}^{-1}$ PAC was carried out using a clean membrane. The flux improvement remained at the $5 \mathrm{LMH}$ level until the solids reached $18 \mathrm{~g} \mathrm{l}^{-1}$, however, with increased loading rate and the correspondingly higher total solids concentration $\left(23 \mathrm{~g}^{-1}\right)$, viscosity increased sharply to $7 \mathrm{cp}$ and then to 14 cp on days 33 and 45, respectively, for the same solids level (data not shown). This higher viscosity resulted in a significant flux drop of $3 \mathrm{LMH}$, and the final flux stabilised at $2 \mathrm{LMH}$. This experiment demonstrated the significance of viscosity on flux decline, and hence the maximum level of solids that can be maintained inside the SAMBR in order to obtain a high flux[careful-this high viscosity could have been due to the high levels of ECP due to specific reactor conditions, and can not be made totally general]. Due to the higher biomass concentrations and viscosity levels, it is difficult to deduce anything about the relative contribution of higher quantities of PAC $\left(3.4 \mathrm{~g}^{-1}\right)$ on flux improvement. If the total solids level including PAC had been controlled to a fixed value below $20 \mathrm{~g}^{-1}$ then the effect of different quantities of PAC on flux improvement could probably be explained more easily. The relative contribution of internal fouling was higher (172 LMH flux decline) in the case of 3.4 $\mathrm{g} \mathrm{l}^{-1}$ of PAC, while the cake layer contribution to flux reduction was lower, and equal to $23 \mathrm{LMH}$ which confirmed that either a thinner cake layer was present due to an increase in backtransport velocity of biosolids, or a cake layer of high porosity was formed as PAC interferes in cake formation by forming a loose and incompressible layer due to its physically rigid structure. Therefore, higher permeability with PAC addition may be due to a change in porosity as the absence of high MW organics in the effluent (Figure 6) shows the possible presence of PAC in biofilm, however, no attempt was made to measure PAC in the biomass collected from the biofilm. 
At the end of the first experiment a thick cake layer had formed on the membrane surface, and PAC equal to $1.67 \mathrm{~g} \mathrm{l}^{-1}$ was added to assess the effect of physical scouring of the cake layer, and to measure any corresponding improvement in flux. After one month no flux improvement was observed, and the flux remained stable at $2 \mathrm{LMH}$. This means that PAC is important in adsorbing colloids and dissolved organics, and interferes with cake layer formation to produce a layer of high porosity and greater permeability, but is ineffective in physical scouring of the compressed biomass cake layer formed on the membrane surface.

\section{CONCLUSIONS}

- SAMBRs can achieve $98 \%$ COD removal efficiency at high loading rates (16 g COD $\left.1^{-1} \mathrm{~d}^{-1}\right)$, even at a low HRT of 6 hours. The addition of PAC helped to improve the start-up period and shock load performance by acting as a buffer to VFAs.

- PAC adsorbs significant amounts of both low and high MW residual COD in the bulk liquid which was difficult to degrade, and hence improves removal performance and flux. The analysis of particle size distribution demonstrated that PAC adsorbs fine colloids in the bulk solution, and flux data showed that a thin layer of biofilm is formed due to high backtransport velocity of biosolids in the presence of PAC.

- The effect of adsorption of colloids and dissolved organics resulted in significant flux improvement from 2 to $9 \mathrm{LMH}$ with the addition of $1.67 \mathrm{~g}^{-1} \mathrm{PAC}$, however, in the presence of $3.4 \mathrm{~g} \mathrm{l}^{-1}$ PAC flux was reduced by the combined effects of 
viscosity and the inability of PAC to adsorb dissolved organics and fine colloids completely which resulted in higher values of internal fouling.

- Size exclusion chromatography showed that the MW cut-off of the membrane was around $30 \mathrm{kDa}$. A better quality effluent was produced during anaerobic degradation of high strength wastewater in SAMBR as the gel layer and pore clogging significantly reduced the amount of organics passing through membrane.

- Based on cost, flux and COD removal improvement, addition of $1.67 \mathrm{~g} \mathrm{l}^{-1}$ of PAC seems to be the optimum quantity for the SAMBRs under the given conditions of operation.

\section{ACKNOWLEDGEMENTS}

AA would like to thank the Ministry of Science and Technology, Government of Pakistan, for the award of a scholarship (Grant number 49 (223) E-37(CE)/2001-DSA (HRD)).

\section{REFERENCES}

[1] Ross WR and Strohwald NK. Application of the ADUF process to brewery effluent on a laboratory scale. Water Science and Technology 1992;25:95-105.

[2] Brindle K and Stephenson T. The application of membrane biological reactors for the treatment of wastewaters. Biotechnology and Bioengineering 1996;49:601610.

[3] Park H, Choo KH and Lee CH. Flux enhancement with powdered activated carbon addition in the membrane anaerobic bioreactor. Separation Science and Technology 1999;34:2781-2792.

[4] Choo $\mathrm{KH}$ and Lee $\mathrm{CH}$. Effect of anaerobic digestion broth composition on membrane permeability. Water Science and Technology 1996b;34:173-179. 
[5] Aquino SF, Hu AY, Akram A and Stuckey DC. Characterization of dissolved compounds in submerged anaerobic membrane bioreactors (SAMBRs). Journal of Chemical Technology and Biotechnology 2006;81:1894-1904.

[6] Brockmann M and Seyfried CF. Sludge activity and cross-flow microfiltration: a non-beneficial relationship. Water Science and Technology 1996;34:205-213.

[7] Bouhabila EH, Aim RB and Buisson H. Fouling characterisation in membrane bioreactors. Separation and Purification Technology 2001;22:123-132.

[8] Ma H, Bowman CN and Davis RH. Membrane fouling reduction by backpulsing and surface modification. Journal of Membrane Science 2000;173: 191-200.

[9] Jeison D and van Lier JB. On-line cake-layer management by trans-membrane pressure steady state assessment in Anaerobic Membrane Bioreactors for wastewater treatment. Biochemical Engineering Journal 2006;29:204-209.

[10] Akram A. Stability and performance improvement of a submerged anaerobic membrane bioreactor (SAMBR) for wastewater treatment. $\mathrm{PhD}$ Thesis Department of Chemical Engineering and Chemical Technology Imperial College London 2007.

[11] Noguera DR, Araki N and Rittmann BE. Soluble microbial products (SMP) in anaerobic chemostats. Biotechnology and Bioengineering 1994;44:1040-1047.

[12] APHA. Standard Methods for the Examination of Water and Wastewater. $20^{\text {th }}$ edition, American Public Health Association Washington DC 1999.

[13] Barker DJ and Stuckey DC. A review of soluble microbial products (SMP) in wastewater treatment systems. Water Research 1999;33:3063-3082.

[14] Owen WF, Stuckey DC, Healy JB, Young LY and McCarty PL. Bioassay for monitoring biochemical methane potential and anaerobic toxicity. Water Research 1979;13:485-492.

[15] Speece RE. Anaerobic biotechnology for industrial wastewaters. $1^{\text {st }}$ edition, Archae Press, Tennessee, USA, 1996.

[16] Hu AY and Stuckey DC. Activated Carbon addition to a Submerged Anaerobic Membrane Bioreactor: Effect on performance, transmembrane pressure, and flux. Journal of Environmental Engineering 2007;133:73-80.

[17] Raposo F, Banks CJ, Siegert I, Heaven S and Borja R. Influence of inoculum to substrate ratio on the biochemical methane potential of maize in batch tests. Process Biochemistry 2006;41:1444-1450. 
[18] Schiener P, Nachaiyasit S and Stuckey DC. Production of soluble microbial products (SMP) in an anaerobic baffled reactor: composition, biodegradability and the effect of process parameters. Environmental Technology 1998;19:391340.

[19] Huang X, Liu R and Qian Y. Behaviour of soluble microbial products in a membrane bioreactor. Process Biochemistry 2000;36:401-406.

[20] Lin CF, Lin TY and Hao OJ. Effects of humic substance characteristics on UF performance. Water Research 2000;34:1097-1106.

[21] Newcombe G, Drikas M and Beckett R. Influence of characterised natural organic material on activated carbon adsorption-II: effect of pore volume distribution and adsorption of 2-methylisoborneol. Water Research $1997 b ; 31: 1065-1073$.

[22] Shin HS and Kang S. Performance and membrane fouling in a pilot scale SBR process coupled with membrane. Water Science and Technology 2002;47:139144.

[23] Shin HS and Kang ST. Characteristics and fates of soluble microbial products in ceramic membrane at various sludge retention times. Water Research 2003;37:121-127.

[24] Laspidou CS and Rittman BE. A unified theory for extracellular polymeric substances, soluble microbial products, an active and inert biomass. Water Research 2002;36:2435-2445.

[25] Aquino SF and Stuckey DC. Soluble microbial products formation in anaerobic chemostats in the presence of toxic compounds. Water Research 2004;38:255266.

[26] Kim JS, Lee $\mathrm{CH}$ and Chun HD. Comparison of ultrafiltration characteristics between activated sludge and BAC sludge. Water Research 1998;32:34433451 .

[27] Li YZ, He YL, Liu YH, Yang SC, and Zhang GJ. Comparison of the filtration characteristics between biological powdered activated carbon sludge and activated sludge in submerged membrane bioreactors. Desalination 2005; $174: 305-314$

[28] Pianta R, Boller M, Janex ML, Chappaz A, Birou B, Ponce R and Walther JL. Micro- and ultrafiltration of karstic spring water. Desalination 1998;117:6171. 
[29] Guo WS, Vigneswaran S, Ngo HH and Chapman H. Experimental investigation of adsorption-flocculation-microfiltration hybrid system in wastewater reuse. Journal of Membrane Science 2004;242:27-35.

[30] Jacangelo JG, Laine JM, Cummings EW and Adham SS. UF with pretreatment for removing DBP precursors. J. Am. Water Works Assoc. 1995;87:100-112.

[31] Braghetta A, DiGiano FA and Ball WP. Nanofiltration of natural organic matter: $\mathrm{pH}$ and ionic strength effects. Journal of Environmental Engineering 1997;123:628-641.

[32] Chang IS and Lee CH. Membrane filtration characteristics in membrane coupled activated sludge system - the effect of physiological states of activated sludge on membrane fouling. Desalination 1998;120:221-233. 
Table 1: Performance of the SAMBRs during the start-up period.

\begin{tabular}{ccc|ccc|ccc}
\hline \multicolumn{2}{c|}{ SAMBR (No PAC) } & \multicolumn{3}{c|}{ SAMBR (1.67 g $\mathbf{l}^{-1}$ PAC) } & \multicolumn{3}{c}{ SAMBR (3.4 g l PAC) } \\
Days & $\begin{array}{c}\text { HRT } \\
\text { (hrs) }\end{array}$ & $\begin{array}{c}\text { \% COD } \\
\text { removal }\end{array}$ & Days & $\begin{array}{c}\text { HRT } \\
\text { (hrs) }\end{array}$ & $\begin{array}{c}\text { \% COD } \\
\text { removal }\end{array}$ & Days & $\begin{array}{c}\text { HRT } \\
\text { (hrs) }\end{array}$ & $\begin{array}{c}\text { \% COD } \\
\text { removal }\end{array}$ \\
\hline $0-12$ & 40 & 96 & $0-6$ & 30 & 97 & $0-8$ & 30 & 97 \\
$13-25$ & 30 & 95 & $7-18$ & 20 & 99 & $9-17$ & 20 & 98 \\
$26-33$ & 20 & 96 & $19-28$ & 6 & 88 & $18-27$ & 12 & 98 \\
$34-42$ & 17 & 97 & $29-32$ & 15 & 99 & $28-32$ & 6 & 98 \\
$43-52$ & 15 & 96 & & & & & & \\
\hline
\end{tabular}

Table 2: Average COD concentrations in the reactor bulk liquid and effluent from each SAMBR under various HRTs.

\begin{tabular}{|c|c|c|c|c|c|c|c|c|}
\hline \multicolumn{3}{|c|}{$\begin{array}{c}\text { SAMBR (Without PAC) } \\
\left(\mathrm{mg} \mathrm{l}^{-1}\right)\end{array}$} & \multicolumn{3}{|c|}{$\begin{array}{c}\text { SAMBR (1.67 } \mathrm{g} \mathrm{l}^{-1} \text { PAC) } \\
\left(\mathrm{mg} \mathrm{l}^{-1}\right)\end{array}$} & \multicolumn{3}{|c|}{$\begin{array}{c}\left.\text { SAMBR (3.4 } \mathrm{g} \mathrm{l}^{-1} \text { PAC }\right) \\
\left(\mathrm{mg} \mathrm{l}^{-1}\right)\end{array}$} \\
\hline $\begin{aligned} \text { HRT } \\
(h r s)\end{aligned}$ & Reactor & Effluent & $\begin{aligned} \text { HRT } \\
(\text { hrs) }\end{aligned}$ & Reactor & Effluent & $\begin{array}{l}\text { HRT } \\
\text { (hrs) }\end{array}$ & Reactor & Effluent \\
\hline 40 & 1792 & 160 & 30 & 419 & 150 & 30 & 200 & 141 \\
\hline 30 & 2597 & 198 & 20 & 327 & 34 & 20 & 374 & 80 \\
\hline 20 & 1817 & 160 & $\begin{array}{c}6 \\
\text { Shock }\end{array}$ & 520 & 484 & 12 & 346 & 92 \\
\hline 17 & 1504 & 140 & 15 & 184 & 31 & 6 & 393 & 70 \\
\hline 15 & 1789 & 150 & & & & & & \\
\hline
\end{tabular}


Table 3: Operational conditions and typical values of main parameters for SAMBR system.

\begin{tabular}{|c|c|c|c|c|}
\hline \multicolumn{2}{|c|}{ PARAMETER/VARIABLE (1) } & SAMBR 1 (1) & SAMBR 1 (2) & SAMBR 1 (3) \\
\hline \multicolumn{2}{|c|}{ Feed composition } & $\begin{array}{l}\text { Sucrose, Meat } \\
\text { extract and } \\
\text { peptone }\end{array}$ & $\begin{array}{l}\text { Sucrose, Meat } \\
\text { extract and } \\
\text { peptone }\end{array}$ & $\begin{array}{l}\text { Sucrose, Meat } \\
\text { extract and } \\
\text { peptone }\end{array}$ \\
\hline \multicolumn{2}{|c|}{ Feed strength (as mg COD $1^{-1}$ ) } & 4000 & 4000 & 4000 \\
\hline \multicolumn{2}{|c|}{ HRT (hours) } & 15 & 6 & 6 \\
\hline \multicolumn{2}{|c|}{ SRT (days) ${ }^{\mathrm{a}}$} & $\sim 250$ & $\sim 250$ & $\sim 250$ \\
\hline \multicolumn{2}{|c|}{ Activated carbon } & No & Yes $\left(1.67 \mathrm{~g} \mathrm{l}^{-1}\right)$ & Yes $\left(3.4 \mathrm{~g} \mathrm{l}^{-1}\right)$ \\
\hline \multicolumn{2}{|c|}{$\operatorname{VSS}\left(\mathrm{mg} \mathrm{l}^{-1}\right)^{\mathrm{b}}$} & 12360 & 11446 & 16116 \\
\hline \multicolumn{2}{|c|}{ Start-up Time (Days) } & 52 & 28 & 30 \\
\hline \multicolumn{2}{|c|}{$\operatorname{OLR}\left(\mathrm{g} \mathrm{COD}^{-1} \mathrm{~d}^{-1}\right)$} & 6.4 & 16 & 16 \\
\hline \multicolumn{2}{|c|}{$\operatorname{SLR}\left(\mathrm{g} \mathrm{COD} \mathrm{g}^{-1} \mathrm{VSS} \mathrm{d}^{-1}\right)$} & 0.52 & 1.40 & 1.0 \\
\hline \multicolumn{2}{|c|}{$\%$ COD removal } & 96 & 88 & 98 \\
\hline \multicolumn{2}{|c|}{ Permeate Flux (LMH) } & 2 & 9 & 5 \\
\hline \multirow{2}{*}{$\mathrm{COD}\left(\mathrm{mg} \mathrm{l}^{-1}\right)$} & bulk liquid & 1789 & 520 & 393 \\
\hline & effluent & 150 & 484 & 70 \\
\hline \multicolumn{2}{|l|}{ COD reactor/effluent } & 12 & 1.1 & 5.5 \\
\hline \multirow{2}{*}{ VFA (as mg COD $1^{-1}$ ) } & bulk liquid & 2 & 292 & 30 \\
\hline & effluent & N.D. & 292 & N.D. \\
\hline \multirow{2}{*}{$\mathrm{SMP}$ (as mg COD $1^{-1}$ ) } & bulk liquid & 1787 & 228 & 360 \\
\hline & effluent & 150 & 192 & 70 \\
\hline SMP/So & bulk liquid & 0.45 & 0.086 & 0.09 \\
\hline
\end{tabular}


Table 4: Contribution of various components of fouling in each SAMBR.

\begin{tabular}{|l|c|c|c|}
\hline \multirow{2}{*}{$\begin{array}{l}\text { Components of } \\
\text { Fouling }\end{array}$} & \multicolumn{3}{|c|}{ Flux drop for different amounts of PAC (LMH) } \\
\cline { 2 - 4 } & Without PAC & $\begin{array}{c}\text { With 1.67 } \mathbf{g ~ I}^{-1} \\
\text { PAC }\end{array}$ & With 3.4 $\mathbf{g ~ I}^{\mathbf{1}} \mathbf{P A C}$ \\
\hline $\begin{array}{l}\text { Biofilm and } \\
\text { Internal Fouling } \\
\text { (F1) }\end{array}$ & $198.0 \pm 0.5$ & $191.0 \pm 0.5$ & $195.0 \pm 0.5$ \\
\hline Biofilm (F2) & $38 \pm 5$ & - & $23 \pm 5$ \\
\hline $\begin{array}{l}\text { Internal Fouling } \\
\text { (F3) }\end{array}$ & $160 \pm 5$ & - & $172 \pm 5$ \\
\hline $\begin{array}{l}\text { Maximum } \\
\text { available Flux } \\
\text { (F4) }\end{array}$ & $200 \pm 5$ & $200 \pm 5$ & $200 \pm 5$ \\
\hline
\end{tabular}

